\title{
CLÁUDIO SOUTO E SOLANGE SOUTO: A SAGA, A SUBSTANCIALIDADE, O INTERSIV
}

\section{CLÁUDIO SOUTO AND SOLANGE SOUTO: THE SAGA, THE SUBSTANCIABILITY, THE INTERSIV}

Artur Stamford da Silva ${ }^{1}$

\section{RESUMO}

Sinônimos de sociologia do direito no Brasil não apenas por suas dedicações ao ensino e à pesquisa nessa área, mas também por seus nomes se confundirem com o surgimento, a continuidade e a existência dessa disciplina em cursos de direito no Brasil, Cláudio Souto e Solange Souto se dedicaram à construção de uma teoria substantiva do direito como justiça, movendo-se em contrafluxo aos modismos, posto que sua teoria é substantiva, axiomática e não coercitiva, em tempos de procedimentalismo, consenso e coercitividade. Estas reflexões estão pautadas por pesquisa bibliográfica baseada em obras dos autores publicadas de 1952 a 2019 e bibliografia secundária. Dentre os achados, observamos a saga do pensar sociologicamente o direito vivenciada por Cláudio Souto e Solange Souto. Outro achado foi quanto à base empírica da teoria substantiva, o sentimento de justiça e da ideia de dever ser como elementos básicos do controle social que foi fruto da análise dos dados da pesquisa realizada em 1965, em Colônia, Alemanha, e replicada mais uma vez no Brasil. Por fim, a relação entre direito e força. A teoria substantiva, parte da indissociabilidade direito e justiça face ao interSIV, do que resulta a coercitividade não ser elemento essencial ao direito.

Palavras-chave: Sociologia do direito; Cláudio Souto; Solange Souto; Escola do Recife; Composto siv.

\section{ABSTRACT}

Synonymous of sociology of law in Brazil not just because the dedication to teaching and research in this area, but also because their names are confused with the emergence, continuity and existence of this discipline in law courses in Brazil, Cláudio Souto and Solange Souto dedicated themselfs to construction of a substantive theory of law as justice, moving against the flow to the fads, since her theory is substantive, axiomatic and non-coercive, in times of proceduralism, consensus and coerciveness. These reflections are guided by bibliographic research based on the authors' works published from 1952 to 2019 and secondary bibliography. Among the find outs, we observe the saga of thinking sociologically about law experienced by Cláudio Souto and Solange Souto. Another find out was regarding the empirical basis of the substantive theory, the feeling of justice and the idea of ought to be basic elements of social control was the result of the analysis of data from the survey carried out in 1965, in Cologne, Germany, and replicated once more in the Brazil. Finally, the relationship between law and force. The Substantive theory starts from the inseparability of law and justice from the interSIV, which results in coerciveness not being an essential element of law.

Keywords: Sociology of law; Claudio Souto; Solange Souto; Recife School; Siv compost.

${ }^{1}$ Professor Titular de Sociologia do Direito da Faculdade de Direito do Recife. CCJ-UFPE. Pesquisador 1D pelo CNPq. 


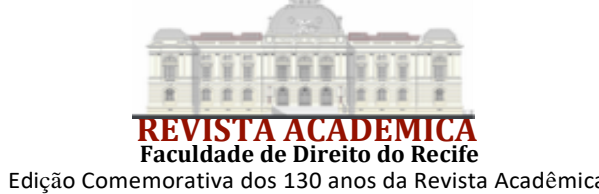

\section{INTRODUÇÃO}

Pensar o Brasil brasileiro não traz qualquer novidade. As leituras de sua história alertam para que 1822 não só "não colocou o Brasil no ritmo da história" (IANNI, 2004, p. 15), como equacionou um país capaz de vivenciar uma monarquia sem reinado, uma república sem partido, um país caudilhista e sem projeto nacional: um Brasil brasileiro de síndrome portugalesca?

Por mais que saibamos o quanto "história não é bula de remédio" (SCHWARCZ, 2019, p. 11), chama atenção o quanto umas histórias perpetuam ideias, concepções, preconceitos sob o manto de justificações racionais; enquanto outras contam registros de conquistas e vitórias e, às vezes, até de superação de preconceitos e desigualdades.

No caso do país do futuro - país com oitava colocação dentre os piores índices de desigualdade social, comparado a 124 países constantes no Relatório de Desenvolvimento Humano do Programa das Nações Unidas para o Desenvolvimento (Pnud) - temos quem comemore com afã nossa capacidade de conviver com IDH de 0,574\% e concentração de renda em menos de 5\% da população ${ }^{2}$.

O Brasil não é para amadores, justo por ser um país muito amador.

Não norteamos, fica dito, nossas reflexões por qualquer idealismo, antes, partimos de que “terra aonde eu não vou, o feijão dá na raiz", ao mote de Adalgisa Falcão. Assim ela se expressava ao se referir ao sonho perfeccionista dos ideais que apontam terras desconhecidas como exemplares. Tão perfeitas, que o feijão não germina, o coleóptilo sequer precisa se formar, os cotilédonos se abrem e lá está o grão de feijão pronto a ser consumido. Não é preciso irrigar, o caule nem nasce para sustentar os brotos e as vargens. Os grãos do feijão simplesmente estão lá, surgidos. Estão lá, simples assim. A serem colhidos na e pela raiz.

Não foi assim, com essa magia que a sociologia do direito teve lugar nos cursos de direito no Brasil. Os embriões Cláudio Souto e Solange Souto vivenciaram uma verdadeira saga pelo pensar sociologicamente o direito (SOUTO, 1987b; SOUTO, 2016, p. 22-38). Essa história registra, já no artigo publicado em 1952 até o artigo publicado em 2019, passando pelos livros e pela bibliografia secundária, o conservadorismo dogmaticopata perpetuado nos intramuros da Faculdade de Direito do Recife. Incrível como em 2021 ainda há quem fale em separação entre dogmática jurídica e os "saberes de outras áreas formativas"3 , principalmente quando alguém ainda defende uma formação jurídica sem as disciplinas propedêuticas ou, já que são saberes obrigatórios a serem oferecidos, que assim sejam ao final do curso. Incrível como é preferível discentes sem reflexividade e treinados a reproduzir textos legislativos e, quando muito, algumas decisões judiciárias. Mas a saga vivenciada por Cláudio e Solange vivenciaram para a sociologia do direito vir a ser disciplina nesta e desta Faculdade ainda resiste. Como escreve Cláudio Souto:

O desenvolvimento da sociologia do direito se caracteriza por dois períodos básicos. O período inicial se marca pela hostilidade tanto de sociólogos como de juristas à sociologia do direito. O segundo período, que alcança nossos dias, tem sido um período de abandono da disciplina por sociólogos e por juristas - embora tal abandono se torne cada vez mais relativo (SOUTO, 1977, p. 1).

Assim, contudo, sobre esse ponto, não desenvolvemos reflexões de história, mas acusamos Cláudio Souto e Solange Souto de importunarem os doutos dogmaticopatas que ainda circulam nos salões conservadores, nos quais se enunciam a hipótese de ser possível prática jurídica sem vida social, de ser possível separar teoria e prática, de ser possível separar direito de sociedade. A estes, a vida evidencia o quando nunca existe o direito dado, que está lá, simples assim. Como todos sabem. Os grãos do direito nunca simplesmente surgem, assim, do nada. Nunca estão lá,

\footnotetext{
${ }^{2}$ Dados obtidos no site do IBGE. https://www.ibge.gov.br/estatisticas/sociais/educacao/9050-pesquisa-deorcamentos-familiares.html?=\&t=0-que-e

${ }^{3}$ Essa é a terminologia emprega na Resolução Nº 2, de 19 de abril de2021, do Ministério da Educação, que rege as Diretrizes Curriculares Nacionais do Curso de Graduação em Direito. No elenco de áreas formativas estão: "Antropologia, Ciência Política, Economia, Ética, Filosofia, História, Psicologia e Sociologia".
} 


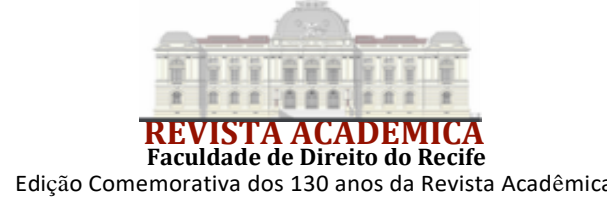

simples assim. Não há direito a ser colhidos na e pela raiz.

Aproveito esta introdução para me desculpar por informar que não há dogmática sem sociologia, pelo menos a dogmática como ciência do direito, afinal, reproduzir texto legislativo e jurisprudência não tem qualquer relação com ciência, muito menos com ciência jurídica, com a dogmática jurídica (SOUTO, 1987b, p. 13-16; SOUTO; SOUTO, 2003, p. 46-49). Simples assim. É o que temos observado nas leituras das tantas reflexões dogmáticas jurídicas publicadas na atualidade. Aos pseudo-dogmáticos: a raiz. Infelizmente, para estes, não desconhecemos que a redução do direito ao estado, ou mesmo ao exercício prático-forense, patrocina um senso comum teórico dos juristas, reduz a informação à "opinião de ofício pela práxis jurídica", o que nutre o sonho de se afastar completamente ou até mesmo eliminar as "vozes dissidentes" pelo enclausuramento via a ortodoxia. Ocorre que "o deslocamento epistemológico não deve ser realizado nem pela supremacia da razão sobre a experiência, tampouco da experiência sobre a razão, mas sim, pelo primado da política sobre ambas" (WARAT, 1982, p. 49).

Só quem anda por terras em que feijão dá na raiz é que pode insistir em isolar o saber jurídico ou na dogmática ou na filosofia ou na sociologia. Pesquisa jurídica requer transdisciplinaridade. Não há saber jurídico sem trânsito pelo fluxo meio teórico e meio empírico (STAMFORD DA SILVA, 2002, p. 6-7). Fazer pesquisa científica permite o desenvolvimento de uma habilidade fundamental ao exercício prático-forense: patrocinar reflexividade, objetividade e organização na exploração dos dados pesquisados para a confecção de uma peça forense (STAMFORD DA SILVA, 2005, p. 33).

Como autoria de teoria científica não se confunde com as aplicações possíveis, após trabalhar a saga, dividimos estas reflexões em outras duas partes. Uma referente ao substancialismo da teoria de Cláudio Souto e Solange Souto, em tempos no qual predomina o procedimentalismo. Após o que, abordamos o composto SIV (Sentimento, Ideia e Vontade) como elemento básico do social humano, do qual partem Cláudio Souto e Solange Souto para desenvolver sua teoria da sociedade, sua explicação sociológica do controle social, do direito.

Assim organizadas estas reflexões, agradeço a Cláudio Souto pelas conversas ao longo dos últimos vinte e cinco anos, mas também pelos esclarecimentos que viabilizaram detalhes fundamentais para que essas reflexões pudessem refletir um mínimo a profundidade da teoria substantiva do controle social como justiça. Agradeço também toda a atenção a mim dedicada por Antônio Souto e Theresa Souto, principalmente ao me disponibilizar textos que não se encontram disponíveis nas bibliotecas nem na internet, além das informações históricas sobre a biografia de Cláudio Souto e Solange Souto.

\section{A SAGA PELA SOCIOLOGIA DO DIREITO NA FDR}

Se há autores desocupados em se promover, Cláudio Souto e Solange Souto são paradigmas, exemplares. Referências da sociologia do direito brasileira, conheci quão fático são seus status de referência internacional em Oñate, no Instituto Internacional de Sociologia do Direito, durante o Congresso de 2009. A palavra Recife era sucedida da pergunta: "- me dê notícias de Cláudio Souto!”. Assim foi com Alberto Febbrajo, André-Jean Arnaud, Angélica Cuellar, Dario Rodriguez Mansilla, Pierre Guibentif, Roger Cotterrell, Vincenzo Ferrari, Wanda Capeller. Não me arisco a sugerir uma causalidade para isso, mas seu currículo registra o quanto participar de eventos não foi atividade a que se dedicou, afinal: participou de um evento em 1979; um em 1981; um em 1985; dois em 1988; e um em 1990. O mesmo se diga de Solange. Os registros mais recentes são de participações em eventos no Recife, como o lançamento de seus livros na Unicap, Livraria Cultura e na Faculdade de Direito do Recife. Fechando a conta, em 2016, Cláudio e Solange participaram do Congresso da ABraSD (Associação Brasileira de Pesquisadores em Sociologia do Direito). Ficam então suas publicações como hipótese: 20 livros e 114 artigos, dos quais quatro em alemão, dois em francês, treze em inglês, quatro em espanhol, cinco em italiano e os demais 


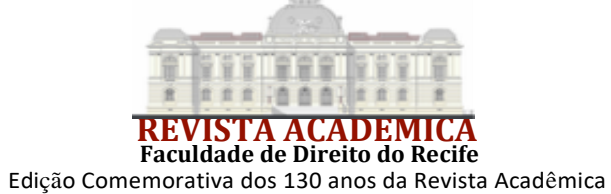

em português.

Ocorre que a obra pode ser qualificada como daquelas que não virou moda, há poucos comentadores, mas atualmente tem surgido mais bibliografias secundárias, como observamos numa busca na internet. Seja como for, devemos a Mirian de Sá Pereira a divulgação das ideias dos autores e o patrocínio da continuidade das ideias de Cláudio Souto e Solange Souto.

Nascido, oficialmente em Garanhuns (JUNQUEIRA, 2021, p. 306), aos 29 de março de 1931 e nascida em 25 de agosto de 1936, efetivamente em Recife, Cláudio Souto e Solange Souto são exemplos de dedicação à pesquisa, exemplos que se enfatizam por seguirem publicando até a atualidade. Atitude esta que incentiva a produção e divulgação do pensar sociologicamente o direito, como ficou patente na homenagem aos 90 anos de Cláudio Souto, com o lançamento do Prêmio ABraSD Cláudio Souto de Teses. Na ocasião, autores de vários cantos do Brasil e autores internacionais participaram não só virtualmente, mas também enviando vídeos homenageando e vídeos comentando suas obras ${ }^{4}$.

Solange Maria de Moura Souto (1936-2021), doutora em Sociologia pela UFPE (1970), foi Professora Titular de Sociologia da UFPE, desenvolveu pesquisa, com bolsa do DAAD, em Bielefeld (Alemanha), em 1982. A dedicação exclusiva como professora e pesquisadora faz de Solange Souto o nome da pesquisadora que marca a história da sociologia do direito no Brasil. Cláudio Fernando da Silva Souto (1931-) teve dedicação exclusiva como Professor Assistente de sociologia na Faculdade de Filosofia do Recife e como Professor Adjunto de direito constitucional da Faculdade de Direito do Recife, à época Universidade do Recife - formada, em 1946, pela Faculdade de Direito do Recife (fundada em 1827), Escola de Engenharia de Pernambuco (1895), Escola de Farmácia (1903), Escola de Odontologia (1913), Faculdade de Medicina do Recife (1915), Escola de Belas Artes de Pernambuco (1932), Faculdade de Filosofia do Recife (1940) (DELGADO, 2016, p. 48). Em 1967 esta Universidade passa a integrar o sistema nacional de universidades, então denominada Universidade Federal de Pernambuco, na qual Cláudio Souto integra o corpo docente do curso de sociologia e do curso de direito, até se aposentar, em 1987.

Essa trajetória foi descrita como estímulo para os que se arvoram a viver de pesquisa séria no Brasil. Não, inclusive, para indicar que o caminho é longo, mas sim que o caminho não termina.

Por que, Saga? Porque diversos incidentes evidenciam a ojeriza nutrida ao pensar sociologicamente o direito como saber pertinente ao curso de direito na Faculdade de Direito do Recife. A aversão pela sociologia nos intramuros da Faculdade de Direito está registrada desde a origem dos cursos jurídicos no Brasil e segue fazendo história. Quem sabe, porque "não era uma tarefa simples para as elites brasileiras abandonar a tão arraigada identidade portuguesa que sintetizava a sua superioridade em relação à população que não tinha essa condição" (APOSTOLOVA, 2017, p. 432).

Não que se falasse em sociologia durante os debates na Assembleia Constituinte de 1823 e que se seguiram na Assembleia Geral Legislativa de 1826 e no Senado. Mas observamos que, na Lei de 11 de agosto de 1827, o nome dos cursos era: Cursos de sciencias jurídicas e sociais.

Os debates de 1823, seguidos pelos que ocorrem ao longo do ano de 1826, registram não apenas as questões referentes às matérias a serem ministradas, mas também que esses cursos não se voltariam exclusivamente à formação de magistrados, mas sim de juristas. É o que lemos com a afirmação de Cunha Barbosa em seu discurso na Assembleia Geral Legislativa: "o jurista pode ser magistrado, publicista, homem de estado, etc." (VENANCIO FILHO, 2011, p. 20). Outros debates foram se se deveria ser criado universidade ou curso e, outro debate foi em que províncias.

Sobre as localidades, pesquisadores concluem que a relação da Coroa com as províncias era permeada não só pelo poder, mas inclusive pela questão de raça, afinal, a capacidade cognitiva de um nativo para ministrar cursos superiores era posta em xeque. Na Assembleia Constituinte, em 14 de junho 1823, José Feliciano Fernandes Pinheiro propõe a criação de uma universidade na

${ }^{4}$ A homenagem, as obras digitalizadas, vídeos (em homenagem e comentando obras), está disponível em: https://www.abrasd.com.br/premio-teses-claudio-souto 


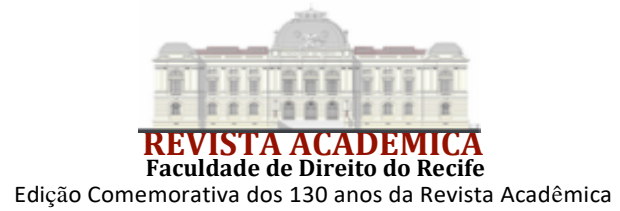

cidade de São Paulo. Na sessão de 11 de novembro de 1823, da Assembleia Constituinte, restou indicada a criação de duas universidades, uma na cidade de São Paulo e outra na cidade de Olinda. Os argumentos quanto ao local se seguiam de desconfianças sobre a capacidade de nesses locais haver pessoas em condições intelectuais para ministrar cursos superiores.

Nessa conjuntura, em 1825, o decreto de 9 de janeiro de 1825 trazia a criação de um curso de direito na cidade do Rio de Janeiro, regido pelo Estatuto de Visconde de Cachoeira, elaborado pelo baiano José Luiz de Carvalho Melo. Com instauração da Comissão de Instrução Pública, em 05 de julho de 1826, é apresentada a criação de um curso jurídico na cidade do Rio de Janeiro. Os debates se seguiram envolvendo criar universidade ou cursos, bem como se se deveria criar cursos jurídicos (VENANCIO FILHO, 2011, p. 13-24; APOSTOLOVA, 2017, p. 445-450; CARNEIRO FILHO; PEREIRA; FARIAS; CALLADO FILHO, 2019, p. 09). O resultado foi a criação de dois cursos de ciências jurídicas e sociais, como lemos na Lei de 11 de agosto de 1827:

Art. $1^{\circ}$ - Crear-se-ão dous Cursos de sciencias jurídicas e sociais, um na cidade de S. Paulo, e outro na de Olinda, e nelles no espaço de cinco annos, e em nove cadeiras, se ensinarão as matérias seguintes (BRASIL, 2021).

Esses dados nos levam a observar não apenas a diversidade de opiniões, mas os argumentos, que foram das condições de se criar uma universidade pátria, de ela ser regida pelo Estatuto da Universidade de Coimbra, de quais disciplinas deveriam ser ofertadas, da nomeação dos lentes, até a exigência de os lentes ministrarem as aulas pautados pelo teor do estatuto de Cachoeira e, no que não couber, que os lentes elaborariam o estatuto do curso.

Relato tais debates e questões apenas para registrar o quanto tratar da função social dos cursos jurídicos é mais complexo que os intramuros de cursos de direito podem supor. Por exemplo, que conteúdo deveria ser ministrado na cadeira Direito romano trouxe à discussão se e o quanto no Brasil se deve reproduzir o estilo "coimbrão" ou não, como afirma Bernardo de Vasconcelos, em discurso na Assembleia Geral Legislativa de 12 de maio de 1826:

Estudei direito público naquela universidade (Coimbra) e por fim saí um bárbaro; foi-me preciso até desaprender. Ensinaram-me que o reino de Portugal e acessórios era patrimonial; umas vezes sustentavam que os portugueses foram dados em dote ao Senhor Dom Afonso I, como se dão escravos e, dotes de bestas ...

\begin{abstract}
Ali não se admitem correspondência com outras academias; ali não se conferem os graus senão àqueles que estudaram o ranço de seus compêndios; ali estava aberta continuamente uma inquisição pronta a chamar às chamas todo aquele que tivesse a desgraça de reconhecer qualquer verdade ou na religião ou na jurisprudência ou na política. Daí vinha que o estudante que saída da Universidade de Coimbra devia antes de tudo desaprender e que lá se ensinava a abrir nova carreira de estudo (VENANCIO FILHO, 2011, p. 22).
\end{abstract}

Justamente pela amplitude de opções que a formação jurídica viabiliza, matérias das ciências sociais foram sugeridas a compor os cursos de ciências jurídicas e sociais. Também foi objeto de debates o momento que as cadeiras deveriam ser ofertadas, prevalecendo o entendimento que deveriam compor os estudos dos primeiros anos (VENANCIO FILHO, 2011, p. 23-24). Assim é porque formar juristas e não rábulas requer uma preparação intelectual que vai muito além da reprodução de texto legislativo, por exemplo, direito natural integrava o primeiro ano do curso e economia política o quarto ano:

1. ANNO: $1^{\text {a }}$ Cadeira. Direito natural, publico, Analyse de Constituição do Império, Direito das gentes, e diplomacia.

2. ${ }^{\circ}$ ANNO: $1^{\text {a }}$ Cadeira. Continuação das materias do anno antecedente. $2^{\text {a }}$ Cadeira. Direito publico ecclesiastico.

3. ${ }^{\circ}$ ANNO: $1^{a}$ Cadeira. Direito patrio civil. $2^{a}$ Cadeira. Direito patrio criminal com a theoria do processo criminal.

4. ${ }^{\circ}$ ANNO: $1^{\text {a }}$ Cadeira. Continuação do direito patrio civil. $2^{\text {a }}$ Cadeira. Direito mercantil e marítimo. 


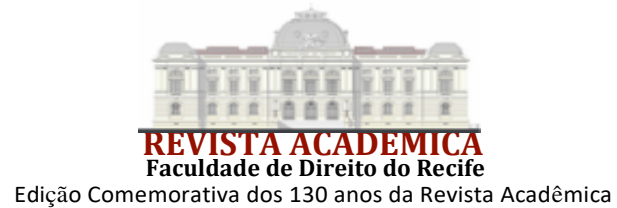

5. ${ }^{\circ}$ ANNO: $1^{\mathrm{a}}$ Cadeira. Economia politica. $2^{\mathrm{a}}$ Cadeira. Theoria e pratica do processo adoptado pelas leis do Imperio (BRASIL, 2021) ${ }^{5}$.

A descrição das diversas alterações curriculares registra debates sobre o tema (PESSOA, 2020, p 211-224), mas não nos ocuparemos delas aqui, mas é incrível como em 2021 ainda há quem defenda, na Faculdade de Direito do Recife, que disciplinas propedêuticas não deveriam existir e, em tendo que existir, que sejam ministras ao final do curso, nem no início nem ao longo do curso.

Para fins de nosso tema, a saga vivenciada para a sociologia do direito vir a ser disciplina do curso de direito da UFPE, lembro que esse tema foi objeto dos debates na construção do Projeto Político Pedagógico de 2013, implementado em janeiro de 2014. Na ocasião, foram realizadas duas reuniões em cada um dos três departamentos, bem como quatro reuniões abertas a todos/as. As três primeiras ocorreram no Espaço Memória e a reunião para discussão e votação dos componentes curriculares ocorreu no Auditório Tobias Barreto.

Já na primeira reunião, no Espaço Memória, os estudantes que compunham um grupo de pesquisa sobre ensino jurídico apresentaram contribuições fundamentais para uma compreensão do que se seguiria aos debates. Demonstraram o levantamento de currículos ministrados nas 20 faculdades de direito mais renomadas do Brasil. Faço esse registro para consignar a importância da veia estudantil nos movimentos reflexivos jurídicos. Dentre as diversas contribuições, saliento a aprovação do princípio norteador aos debates sobre os componentes curriculares que todo semestre deveria conter, no mínimo, uma matéria propedêutica. Outro princípio foi que a carga horária até então já prevista para as matérias propedêuticas não poderiam ser reduzidas, assim, houvesse redução da carga horária de uma disciplina propedêutica esta carga horária deveria ser destinada a outra disciplina propedêutica. Esses princípios foram respeitados apesar das diversas tentativas de burlá-los ao longo dos debates. Esses dados estão registrados em áudios por Artur Stamford da Silva, Coordenador à época, cuja gravação foi devidamente autorizada por todos os presentes.

A saga da rejeição à sociologia também está registrada no período da Escola do Recife e da Geração de 1870, como consta da divergência entre Tobias Barreto e Silvio Romero sobre a concepção de ciência:

Tobias posiciona-se contra Sylvio, negando cientificidade à sociologia, de alguma maneira contradizendo-se, contudo, na aceitação do direito como ciência. Difícil de entender a ojeriza de uma personalidade aberta como a de Tobias à sociologia, aversão que se compreende mais facilmente em alguns pobres de espírito na Faculdade de Direito de nossos dias. Principalmente se, se tem em conta o amor de Tobias pela filosofia do direito e sua visão superadora do evolucionismo de Spencer e, Sylvio, na medida em que não considerava a evolução um dado inexorável e constituído, mas sim um processo mais sisífico, susceptível a contradições, avanços e recuos (ADEODATO, 2003, p. 309).

Uma hipótese poderia ser o olhar divergente que a sociologia do direito patrocina ao pesquisador. Essa hipótese pode ser sustentada com os dados do caso do concurso prestado por Sílvio Romero, em 1875, durante o qual, aos 12 de março, durante a arguição da tese, Sílvio Romero afirma ao arguidor Coelho Rodrigues:

- A metafísica não existe mais. Se não sabia, saiba!

- Não sabia (retruca o arguidor).

- Pois vá estudar e aprender para saber que a metafísica está morta.

- Foi o senhor que a matou?

- Foi o progresso, foi a civilização (VENANCIO FILHO, 2011, p. 98).

O caso resultou que o primeiro lugar não foi nomeado. Sílvio Romero só veio se ser nomeado lente substituto da Faculdade de Ciências Jurídicas e Sociais em 1882.

Evidente, com todos sabemos que história não é bula de remédio, repito o já escrito na

${ }^{5}$ Para ver as alterações porque que passaram as 


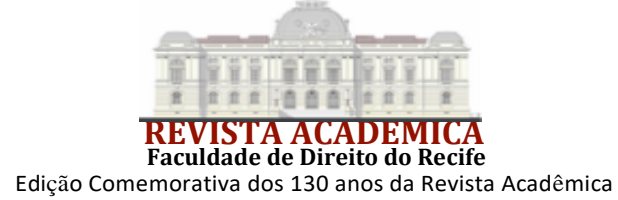

introdução. Agora, para registar que a história da rejeição à sociologia se faz em saga vivida por Cláudio Souto e Solange Souto e, mais uma vez, estudantes protagonizam movimentos. Em 1959, a convite dos estudantes da Faculdade de Direito do Recife, Cláudio Souto realizou reuniões para tratar de sociologia do direito sem qualquer validade curricular. Em 1963, novamente a convite dos estudantes da FDR, Cláudio Souto, ao subir as escadarias se depara com o Diretor, que lhe recepciona anunciando a impossibilidade de ser ministrado o curso por não haver sala disponível, quando então os estudantes propuseram que o curso fosse ministrado no Parque 13 de Maio e assim foi. Perde a FDR a oportunidade de se inscrever como protagonista de feitos históricos nacionais.

Oportunidade que a Unicap não deixa passar. Sob a batuta de Mirian de Sá Pereira, Cláudio Souto, professor fundador da Faculdade de Direito da Universidade Católica de Pernambuco, ministra, em 1962, o primeiro curso de sociologia do direito oficialmente reconhecido como tal, num currículo de curso de direito. Esse feito é até hoje reconhecido e considerado o marco da criação da sociologia do direito no Brasil, ao ponto de a Associação Brasileira de Pesquisadores em Sociologia do Direito (ABraSD) ter criado o Prêmio ABraSD de Teses Cláudio Souto ${ }^{6}$.

Voltando à FDR, em depoimento, Ana Lúcia Falcão ${ }^{7}$ relata que em 1985, durante debates sobre a mudança curricular do curso de direito, mais uma vez os estudantes, dessa vez com apoio de alguns docentes, apresentaram um abaixo-assinado defendendo a inclusão da cadeira de sociologia do direito como disciplina eletiva, com o título de "Teoria e Pesquisa em Sociologia Jurídica" (SOUTO, 2016, p. 27).

Ainda registrando a saga, deve-se a João Maurício Adeodato a inclusão da sociologia do direito como disciplina obrigatória aos cursos de mestrado e doutorado em direito da UFPE, em 1989, a qual foi ministrada por Cláudio Souto e Solange Souto até suas aposentadorias.

Em continuidade da saga na graduação, mesmo com a Portaria MEC No. 1.886/1994, a qual institucionalizou as diretrizes curriculares dos cursos jurídicos, a sociologia configurou como disciplina do eixo de formação fundamental, ao lado de filosofia e teoria do direito. As ideias que deram lugar a esta inclusão se seguiram presentes na Resolução CNE/CES N ${ }^{\circ}$. 9, de 29 de setembro de 2004, na Resolução CNE/CES Nº. 5, de 17 de dezembro de 2018 e na Resolução CNE/CES No. 2 , de 19 de abril de $2021^{8}$.

Contudo, se em 1994 a sociologia do direito foi considerada matéria indispensável à formação dos juristas, a saga chega em 2014, quando sociologia do direito veio a se tornar disciplina do curso de direito da UFPE, com a implementação do perfil curricular 0807. Até então, sociologia do direito era disciplina do curso de sociologia da UFPE (SOUTO, 2016, p. 29).

\section{A TEORIA SUBSTANTIVA}

A história de pesquisador de Cláudio Souto começa no bacharelado em Ciências Jurídicas e Sociais, obtido em 1953, pela Faculdade de Direito do Recife (FDR), do qual seguiu, em 1954, com o doutoramento em direito na FDR, concluído em 1957, com a tese: "Da Inexistência Científico-Conceitual do Direito Comparado: conceituação do indagar comparativo mais específico da Ciência do Direito". Segue sua trajetória quando em 1962 é aprovado na DocênciaLivre da disciplina Introdução à Ciência do Direito, da Faculdade de Direito do Recife, com a tese "Da Irrealidade Jurídico-Definitiva do Direito Natural: nova visualização do fenômeno jusnaturalista”. Seguiu para pós-doutoramento na Alemanha, Universidade de Colônia, com bolsa de pesquisador da Fundação Alexander von Humboldt, num primeiro período em 1965 e, noutro, em 1970. Ainda se considerando em formação, obtém título de doutor em Ciências Sociais pela Faculdade de Sociologia da Universidade de Bielefeld, Alemanha, em 1982, logrou a menção "sehr

\footnotetext{
${ }^{6}$ https://www.abrasd.com.br/premio-teses-claudio-souto

Ver: https://www.abrasd.com.br/premio-teses-claudio-souto?pgid=kmnwyq3x-7be2198c-cf41-4d73-b7debb6983c910a3. Aos 0:30 segundos do depoimento, até os 1:33 minutos.

${ }^{8}$ Para acessar essas resoluções ir em: http://portal.mec.gov.br/component/content/article?id=12991
} 


\section{gut" com a tese "Allgemeinste wissenschaftliche Grundlagen des Sozialen" (Fundamentos} científicos gerais do social).

Em artigo publicado em 1952, já escrevia Cláudio Souto sua ideia de "unicidade causativa societária", na qual a explicação da vida humana em sociedade está vinculada à solidariedade. Assim é porque "a globalidade de aceitação da solidariedade social como dever ser, demonstra o que se nos permita chamar sua unicidade causativa societária ou uma primeira basicidade como princípio gregário, no que tange ao equilíbrio da sociedade humana" (SOUTO, 1952, p. 10). Essa ideia segue presente até o artigo publicado em 2019, quando apresenta 23 teoremas ${ }^{9}$ de sua teoria

9 1. Nos espaços físico, mental e social, quanto menos espaço, menos tempo; e, quanto mais espaço, mais tempo. 2. Nos espaços físico mental e social, quanto maior a ideia de semelhança no sistema interativo (e consequentemente quanto maior a agradabilidade do sentimento), tanto mais rapidamente a passagem do tempo será experimentada. 3. Havendo força de repulsão entre polos interativos nos espaços físico, mental e social, quanto maior a distância entre esses polos, menor a força repulsiva entre eles. 4. Havendo força de atração entre polos interativos nos espaços físico, mental e social, quanto menor a distância entre esses polos, maior a força atrativa entre eles. 5. Nos espaços físico, mental e social, (ceteris paribus) se há agradabilidade do sentimento (correspondente a aproximação), a eventual intensidade emocional é menor, com menor dissipação de energia, do que se há desagradabilidade do sentimento (correspondente a afastamento). 6. Nos espaços físico, mental e social, se há equilíbrio permanente do sistema interativo, o processo resultante é associativo (integrativo). 7. Nos espaços físico, mental e social, quanto maior a semelhança entre os polos interativos (tal como definida em função do que aceitam), tanto maior o equilíbrio do sistema interativo. 8. Nos espaços físico, mental e social, quanto menor a distância entre polos interagentes, tanto maior é o índice relativo de interação entre eles (a relatividade do índice de interação é referente ao número dos polos interagentes, e esse índice é da frequência e duração do processo interativo). 9. Nos espaços físico, mental e social, se a ideia de semelhança é maior do que a necessária para o equilíbrio permanente do sistema interativo, o processo resultante é da maior agradabilidade (=maior suavidade afetiva=paz). 10. Nos espaços físico, mental e social, quanto maior a paz do sistema interativo, maior o equilíbrio desse sistema. 11. Nos espaços físico, mental e social, quanto maior a padronização (uniformização) do elemento ideia de polos interativos, tanto maior a semelhança entre esses polos e consequentemente tanto maior o equilíbrio do sistema correspondente de interação. 12. Nos espaços físico, mental e social, se polos interativos têm seu elemento "ideia" padronizado de maneira científico-empírica, nessa medida há a máxima possibilidade de convicção de que esse elemento "ideia" corresponda à realidade e, portanto, a máxima possibilidade de padronização de tal elemento "ideia"; consequentemente, há a máxima possibilidade de equilíbrio do sistema correspondente de interação (=máxima possibilidade de paz). 13. Nos espaços físico, mental e social, se polos interagentes têm o seu elemento "ideia" padronizado, inclusive científico-empiricamente, na extensão dessa padronização, o elemento "sentimento", no sentido geral do sentimento de agradabilidade, é o fator principal da mudança (alteração menor ou maior) do sistema interativo correspondente (e não já o elemento "ideia", que, nessa extensão, pode ser considerado uma constante). 14. Nos espaços físico, mental e social, quanto maior o equilíbrio do sistema interativo, tanto mais prontamente ele controla qualquer acontecimento que possa perturbar a integração do sistema. 15. Nos espaços físico, mental e social, quanto menor a distância entre polos interativos, tanto menos energia será necessária para comunicação e controle. 16. Nos espaços físico, mental e social, na interação da paz, há o mínimo de energia necessária para comunicação e controle. 17. Nos espaços físico, mental e social, a mudança é uma constante, sendo que quanto maior a ideia de semelhança entre polos interativos, tanto maior o equilíbrio do sistema respectivo de interatos e tanto menos linguagem material (linguagem condensada em signos materiais) é necessária para a comunicação e controle - seja esta comunicação dialogal interna (diálogo mental do indivíduo consigo mesmo), ou exteriorizada. 18. Nos espaços físico, mental e social, quanto mais a socialização (exposição a padrões sociais) se faça no sentido da semelhança entre polos interativos, tanto maior o equilíbrio do sistema de interatos correspondente a tais polos. 19. Nos espaços físico, mental e social, quanto mais a socialização se faça no sentido da semelhança entre polos interativos, tanto mais paz. 20. Nos espaços físico, mental e social, na medida em que a socialização se faça em termos de dessemelhança entre polos interativos, nessa medida os polos assim socializados tenderão a conduta desequilibrante do sistema interativo. 21. Nos espaços físico, mental e social, quanto maior o afastamento pela ideia de dessemelhança, maior a desagradabilidade. E quanto maior a desagradabilidade, tanto maior a tendência para o conflito (conflito mental: conflito interno, ou conflito externo: luta). 22. Nos espaços físico, mental e social, na aproximação pela ideia de semelhança, quanto maior a aproximação, maior a agradabilidade, e, quanto maior esta última, maior a tendência, para a cooperação e a paz, com maior estabilidade da integração. E quanto maior a competição ("luta pacífica", processo de afastamento nos espaços mental e social), maior a instabilidade da integração mental e social. 23. Nos espaços físico, mental e social, (definida cientificamente a justiça como sentimento de agradabilidade diante do que se acha que deve ser,) se um sistema de interatos é considerado essencialmente (principalmente) justo por um ou mais polos interativos (e portanto essencialmente semelhante ao que eles aceitam), tais polos experimentam uma situação de relativa e saudável suavidade afetiva. Caso contrário, as 


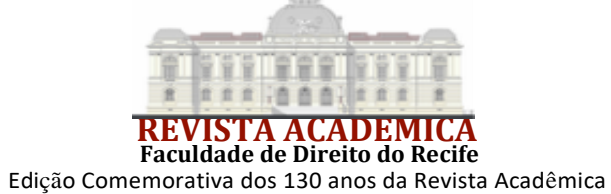

substantiva (SOUTO, 2019, p. 7-10).

Se há uma consequência do tecnocracismo da modernidade, é a ênfase no procedimentalismo, inclusive patrocinando uma "enchente legislativa e processual" (SOUTO; SOUTO, 2003, p. 214). Ideias calcadas em conteúdo foram afastadas da teoria da justiça, do direito e da sociedade. Como ocorre com o positivismo jurídico ao ocupar seu lugar e espaço na sociedade moderna, principalmente o positivismo jurídico pautado por uma objetividade que pretende a separação entre direito e ética. Nessa visão, direito, como produto humano, é procedimento e o conteúdo é consequência da justeza procedimental, quando tem lugar o direito à ampla defesa, o duplo grau de jurisdição, o princípio do juiz natural.

Com a sociologia, a ideia de justiça também teve sua tendência ao procedimentalismo. Cláudio Souto, agora pesquisando com Solange Souto, se inscrevem como dos raros pesquisadores que aportam no substancialismo, principalmente se se pretende uma explicação sociológica da vida em sociedade, portanto do controle social (SOUTO; SOUTO, 1985). A base de sua teoria do controle social é o dever ser como justiça (SOUTO, 1971, p. 33).

Para os autores, não há direito apenas porque determinada legislação foi aprovada pelos trâmites legais, pois é possível haver lei estatal que promova violência. Direito não se reduz à força porque ele é justamente o que diferencia a violência do justo, portanto, direito de violência, física ou psíquica. A obediência à força não é sequer poder. Essa não passa de uma perspectiva formal do direito que, encantadora ao mesmo tempo em que enganosa, afinal, patrocina a hipótese de o medo explicar o social humano e não a agradabilidade (SOUTO, 1981, p. 33). Nessa base, direito "é a formulação científico-positiva insuperável do sentido básico permanente do dever ser" (SOUTO; SOUTO, 2003, p. 220-221). Não se trata de negar justiça a toda e qualquer norma estatal, mas sim de que não toda norma é justa porque estatal. Inclusive, não toda lei emanada de poder é direito. Mas, qual o sentido de direito? Que conteúdo garante direito justo?

A alternativa dos autores é apostar num critério objetivo e, para eles, o único saber objetivo possível é o saber científico. Como a explicação do social, pela observação controlada dos fatos, viabiliza-se a objetividade necessária para uma explicação do direito. Assim é que Cláudio e Solange consideram a ciência como única via para se identificar e conhecer os elementos constitutivos do direito: "conhecimento científico-substantivo" (SOUTO, 2014, p. 40). Quanto a este ponto, chama nossa atenção a aposta na causalidade via a cientificidade. A visão de ciência é a da física, aos moldes de Issac Newton (SOUTO, 1983, p. 9; SOUTO, 2014, p. 44). Contudo, alertam os autores, não se trata de defender uma "definição definitiva" do direito, mas sim da possibilidade de uma

definição tão exata quanto possível, que possa integrar uma explicação teórica satisfatória. Uma apresentação axiomática de construção teórica rigorosa se pode reduzir o mais possível o número das proposições (teses), que devem ter o maior conteúdo informativo possível, ou seja, que devem explorar o maior número possível de dados particulares (SOUTO, 1983, p. 8).

Cláudio e Solange seguem com esta aposta de explicação sociológica até o último artigo publicado (2019, p. 2-12), no qual a ideia de axiomas explicativos ao social humano segue exposta e tratada como observações rigorosas, inclusive quando distinguem o saber dogmático, do filosófico e do sociológico (SOUTO, 1983, p. 11-13; SOUTO, 1986, p. 149-156; SOUTO; SOUTO, 2003, p. 46-49).

Neste ponto, Cláudio e Solange são bastante críticos quanto à possibilidade de se reduzir uma explicação do fenômeno social jurídico à dogmática jurídica. Principalmente na sociedade que tem o judiciário como instituição voltada à promoção e realização da ideia de justiça (SOUTO, 1971; SOUTO, 1983, p. 200; SOUTO, 1989, p. 23; SOUTO, 1978, p. 33). As críticas principais

situações oscilantes de agradabilidade e desagradabilidade, sobretudo as de desagradabilidade, desde que não são situações relativamente suaves, favorecem condições patológicas desequilibrantes no indivíduo e consequentemente no sistema interativo de que se trate. 


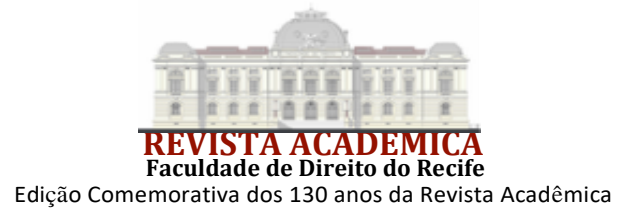

são contra uma formação estritamente dogmática dos juristas, pois essa formação resulta num afastamento de reflexões sobre o social humano e tornam a aplicação do direito um estranhamento para a própria sociedade ao pondo de patrocinar um afastamento do direito ao social humano, afinal a mentalidade jurídica não tem como ignorar a vida em sociedade porque pseudos dogmáticos assim vivem seus sonos jurídicos (SOUTO; SOUTO, 1988, p. 71; SOUTO, 1989, p. 27).

Esse contrassenso é explícito face à ciência moderna, a qual se desenvolve com o ceticismo sobre o saber pela imposição de conhecimento, tanto pela via da imperatividade da força religiosa como da política, como se registra na idade média. Porém, ao recorrer a Isaac Newton para seguir sua concepção de uma explicação sociológica do direito pautada por axiomas, Cláudio e Solange creditam na pesquisa científica a única via para se equacionar elementos constitutivos do direito. Ainda que bastante crítico à dogmática como estudo de leis e jurisprudências, os autores acostam na interdisciplinaridade a cientificidade jurídica (SOUTO, 1986, p. 61-69; SOUTO, 2014, p. 39). A dogmática, a filosofia e a sociologia são inseparáveis, nenhuma delas isoladamente é capaz de produzir ciência do direito (SOUTO, 1987a, p. 199; SOUTO, 2003, p. 46-49).

Assim, o ensino do direito interdisciplinar é a única alternativa para a formação de juristas capazes de desenvolver o direito como dever ser justo, pois a formação ideologizada por um dogmatismo sem reflexividade jamais patrocinará isso (SOUTO, 1977, p. 39-40; SOUTO, 1981, p. 31).

Outro ponto central da teoria substantiva é a diferenciação entre indivíduo e pessoa humana. A sociologia lida com a pessoa humana e não com o indivíduo. Essa distinção é basilar para se considerar o quanto idiossincrasias, elementos da individualidade não são suficientes para se observar o mundo social, todavia, consideram que somos individuais e coletivo ao mesmo tempo. Assim, a teoria sociológica jurídica de Cláudio e Solange parte do ser humano como integrado e influenciado por elementos do mundo externo (mundo, pessoas, cultura, a objetividade) ao mesmo tempo em que por elementos do mundo interno (orgânico, químico, físico corpóreo e psíquico, a subjetividade) (SOUTO; SOUTO, 1985, p. 85-90). Com isso, uma explicação do social humano não pode se limitar a elementos do mundo externo ou do mundo interno, afinal, o ser humano tanto é constitutivo de respostas e ajustes ao meio quanto às exigências sociais, bem como aos desejos, sentimentos, afetos (SOUTO; SOUTO, 2003, p. 24; 30$33)$.

Com esse desenho, Cláudio Souto e Solange Souto concluem que o social não se constitui de luta, de agressividade, de violência, mas de agradabilidade, pois o social é possível devido ao que une, não ao que distancia. Se é assim, por mais que não seja possível estabelecer um

[...] determinismo de fenômenos sociais particulares, como os econômicos, os políticos e até os de crença (que são mais gerais que os primeiros), pode muito bem existir um determinismo das categorias mais altamente genéricas, como ideia, sentimento, vontade, semelhança, distância mental, distância social (SOUTO, 2014, p. 46).

Assim é porque "Os movimentos de atração e repulsão se fazem, de modo basilar, no caso humano, em relação ao siv, ao intersiv (interação mental) e ao intersiv exteriorizado (interação social)" (SOUTO, 2014, p. 45). É que os elementos básicos constitutivos do humano são: sentimento, ideia e vontade. Esses três elementos básicos são moldados como características da realidade social, portanto, relativos à espacialidade, temporalidade e atualidade (SOUTO, 1953, p. 23).

O dever ser, portanto o sentimento, ideia e vontade de justiça, sempre estará revestido das mesmas características, das mesmas "colorações éticas", todavia, "para atuar com força obrigatória efetiva, ainda exige a forma das instituições sociais" (SOUTO, 1953, p. 24). Para os autores, nossa capacidade de selecionar determinados estímulos conta com influências de fatores como frequência, intensidade, movimento e massa (número de objetos, densidade). Assim, as bases para uma formulação axiomática do social humano, especificamente, do social jurídico humano, 


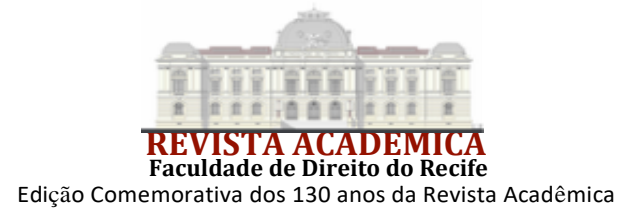

contam com uma base de fatores do mundo externo ao humano e de fatores internos, como são: a visão de mundo, as crenças, as preferências, os sentimentos. Sendo assim:

O objeto da sociologia é estudar cientificamente - de uma maneira mais rigorosa, causal, quanto possível, ou de modo menos rigoroso - os fatos sociais em si mesmos, que são, justamente, em geral, tudo aquilo que resultada do interrelacionamento exteriorizado de pólos mentais individuais (SOUTO; SOUTO, 2003, p. 26).

Para desenvolver essa perspectiva, Cláudio Souto e Solange Souto se dedicaram a identificar quais os elementos básicos do social humano e concluem que são: o sentimento, a ideia e a vontade (o composto S.I.V.). Assim é porque "a interação social ou a ação social, ou o fato social, pode ser definida como a ação relacionada e exteriorizada de pelo menos dois polos siv" (SOUTO; SOUTO, 1973, p. 3). Com isso, temos que "o fato social, sendo intersiv, é internormativo, é igual, em última análise, à norma comunicada na interação social ou norma social" (SOUTO; SOUTO, 1973, p. 3), afinal, uma norma exclusivamente individual não só é extremamente rara no ser humano, como não constitui uma norma jurídica, afinal, não há direito de um só (SOUTO; SOUTO, 1975, p. 191). O ser humano não é uma entidade isolada, não desenvolve seus valores, seus sentimentos e seus conhecimentos sem participação de outros humanos. Não por isso, o ser humano se reduz à cultura, pois o coletivamente se instaura como valores sociais aceitáveis e norteadores do convívio, mas o coletivo não elimina a idiossincrasia. Porém, socialmente, não se conhece idiossincrasia senão como manifestação humana, por isso, interativamente. Sendo assim, o sentimento, a ideia e a vontade não é individuada, mas da pessoa humana, portanto não se trata de $S I V$, mas sim de interSIV.

Uma consequência disso é que o social é necessariamente mudança justamente porque comporta a individualidade e a coletividade simultaneamente.

Como suas pesquisas são voltadas ao direito, controle social se inscreve como questão central das pesquisas de Cláudio e Solange. A não redução do direito ao estado nem a um consenso social, leva os autores a concluírem que "a ordem social seria impossível sem haver diferença entre as pessoas diferentes" (SOUTO; SOUTO, 2003, p. 27). O social, não elimina a diferença, afinal, padronização perfeita não existe. Padronização, o mínimo existencial, não é univocidade completa pela simples obviedade de que sempre haverá diversidade sexual, de idade, de cor, de força física corporal, de limites e diferenças corporais etc. (SOUTO; SOUTO, 2003, p. 26-28).

Nessa perspectiva, socialização é processo de aprendizagem, não apenas porque nascemos associais, mas também porque o convívio de culturas distintas evidencia o quando somos capazes de aprender inúmeros papéis sociais simultaneamente, necessários à formação do social, da ordem social, da continuidade do social, não por isso eivado de conformidade, mas sim com elementos de conformidade ao mesmo tempo em que de processos de conflito, portanto, de acomodação, assimilação, acordo, fusão e tolerância, inclusive porque "um conflito pode prevenir conflitos maiores" (SOUTO; SOUTO, 2003, p. 36), bem como, "o social é sempre mudança" (SOUTO; SOUTO, 1974, p. 3) e, nesse aspecto, controle não se confunde com dominação, a legitimidade não é o que é conforme a lei estatal, afinal, o controle social pode mascarar a imposição, a ilegalidade (SOUTO; SOUTO, 2003, p. 37).

Não ignoram os autores, contudo, que o direito se constitui geralmente pela força, porém esse elemento não é definidor nem constitutivo do direito, mas da violência. Evidente, registros históricos evidenciam o lugar da força na imposição de regras, todavia, para uma regra ser direito, para ela se constituir de legitimidade e ser direito não é fundamental conter força, afinal "o mundo coercitivo dos juristas", não tem por que se reduzir à perspectiva formal do direito, não tem porque valorizar a forma para ser tratado com validação científica e, portanto, contar com certeza científica em oposição à certeza imperativa dos juristas. Nesse sentido, para Cláudio e Solange, o direito como fato social não se reduz a sentimentos de vingança, a obter aceitação e obediência por imposição e medo. Direito é formado justamente pela convivência humana pacífica, pela não violência. Assim, inclusive, é que não cabe confundir direito com moral ou equidade, mas sim 


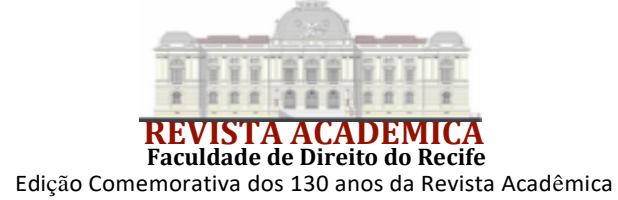

como pauta de conduta, de conduta justa. Afinal, o direito é contra fático, ou seja, independe da visão, da concepção de justiça individual, o direito prevalece aos anseios e desejos pessoais (SOUTO; SOUTO, 2003, p. 222). O limite está em que, para se configurar como direito, o agir humano não pode contar com violência. Com isso, os autores distinguem a formalidade e informalidade no controle social pelo direito (SOUTO; SOUTO, 1997, p. 435-448). Não por isso concordam com Max Weber e com Eugen Erhlich quanto à concepção de direito. A discordância está em que o direito não é violência formal ou informal, como queira Weber, nem direito é

Como então haver direito? Que axioma pode constituir uma explicação científica do direito que não conte com alguma forma de imposição social? Afinal, direito não é consenso. A resposta parte da pergunta: quais os fatores que viabilizam a vida humana em sociedade? As pesquisas levaram os autores a observar que não é a força, a submissão, o dever, afinal, o ser humano não se constitui exclusivamente de terror, medo, obrigações. O humano é composto por afetividade, percepção e querer. Esses três elementos são os básicos constitutivos do humano, os quais são formulados como o composto S.I.V.

\section{O COMPOSTO S.I.V.}

Como acima já anunciado, sentimento (S), ideia (I) e vontade (V) são os elementos básicos constitutivos do humano em sociedade, deve-se a esses elementos a convivência humana em sociedade.

Ocorre que tais elementos não são separáveis, mas imbricados entre si, todavia, por abstração, os autores os distinguem para explicar a sociabilidade humana. Neste ponto cabe lembrar que os autores partem de que a sociedade é normativa. "O social é normativo porque o social é sempre mudança, mesmo quando é controle" (SOUTO; SOUTO, 2003, p. 24). Nessa perspectiva, voltamos a lembrar que indivíduo é diferente de pessoa humana. Esta última é o indivíduo socializado, portanto influenciado simultaneamente pelo mundo externo e pelo interno, afinal a sociedade é possível devido à adaptação da pessoa humana ao meio físico, biológico e social. Com isso, o elemento básico do controle social é o composto S.I.V.

Cláudio Souto e Solange Souto chegaram a estes elementos desenvolvendo pesquisas sobre as regras de comportamento adequado, o mínimo de padronização que viabiliza a transformação do indivíduo em pessoa humana. A primeira pesquisa que deu lugar ao desenvolvimento da teoria foi realizada em 1965 na cidade de Colônia, Alemanha, quando foram entrevistados 290 estudantes de diversos países. Ao analisar os dados da pesquisa, os autores puderem verificar percepções de justiça de pessoas de diversas culturas (SOUTO; SOUTO, 2003, p. 307). Para uma visualização esquemática, construímos o seguinte quadro:

Quadro 1 - Composto S.I.V.

\begin{tabular}{|c|c|c|c|c|c|}
\hline Elemento & base & motivação & agir & Controle & dever ser \\
\hline S & afeto & estímulo & querer & agradabilidade & de justiça \\
\hline I & razão & guia & saber & correição & de justiça \\
\hline V & ânimo & zelo & empenho & força & de justiça \\
\hline
\end{tabular}

Fonte: o autor

O elemento S (sentimento) não é apenas do indivíduo, mas, por ser constitutivo do social humano, é já resultante de socialização, portanto, da pessoa humana. Isso implica que se trata do sentimento de dever ser enquanto "sentimento de que certas coisas podem ser feitas e outras não" (SOUTO; SOUTO, 2003, p. 194; 315-316). A pergunta de partida aqui foi a noção de consciência de injustiça. Com a pesquisa, os autores identificaram que não há uma separação clara entre sentimento e ideias de justiça, pois as respostas à pergunta sobre o sentimento de justiça envolviam uma explicação racional desse sentimento. Porém, há a distinção entre sentir agradabilidade quando se está experimentando, observando, vivenciando algo justo. Esse é o elemento sentimento, 


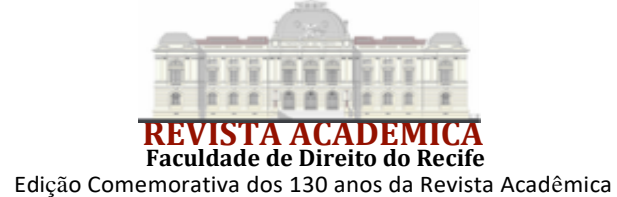

pois independentemente de sua cultura, o respondente responde ter sentimento de justiça por sentir agradabilidade com determinada ideia de justiça. Contudo, quando se tratava de injustiça, o elemento sentimento aparecia relacionado com uma explicação, uma razão para justificar o sentimento, portanto uma ideia de justiça.

Sentir justiça, então, concluem os pesquisadores, estaria vinculado à agradabilidade e sentir injustiça à desagradabilidade. Não todos os entrevistados responderam sentir agradabilidade, uns responderam sentir indiferença ao caso expresso na pergunta da pesquisa. O mesmo foi observado quanto à injustiça. Porém, o que a pesquisa apura é que não há sentimento de agradabilidade diante de injustiça, nem sentimento de desagradabilidade diante da justiça. Assim, independente da concepção de justiça, o sentimento de justiça está relacionado a uma agradabilidade, enquanto o de injustiça, a uma desagradabilidade. Esse dado levou Claudio Souto e Solange Souto elaborarem o seguinte axioma:

\begin{abstract}
5. Nos espaços físico, mental e social, quanto maior a ideia de semelhança, maior a agradabilidade, e o sentimento de agradabilidade, ou de preponderante agradabilidade diante de algo, sempre causa, respectivamente, aproximação, ou uma resultante de aproximação, em direção a esse algo, com emissão da energia de ondas mentais equilibrantes (coesivas, integrativas).

-- Inversamente, quanto maior a ideia de dessemelhança, maior a desagradabilidade, e o sentimento de desagradabilidade ou de preponderante desagradabilidade diante de algo sempre causa, respectivamente, afastamento, ou uma resultante de afastamento, quanto a esse algo, com emissão da energia de ondas mentais desequilibrantes (descoesivas, desintegrativas) (SOUTO, 2018, p. 8-9).
\end{abstract}

Em resumo: quanto ao elemento ideia de justiça (I), que assim como o elemento sentimento de justiça (S), não se dá isoladamente, os autores concluem que o dever ser de justiça não se explica exclusivamente por sentimentos ou por racionalidade, mas pela copresença desses dois elementos, contudo, a racionalidade, a razão com a qual alguém se associa a uma ideia de justiça requer uma validação, validação esta que requer conhecimento científico (SOUTO; SOUTO, 2003, p. 200).

A vontade (elemento $\mathrm{V}$ do interSIV) está relacionada ao agir, à motivação. Não só o sentimento e a ideia de dever ser explica a vida em sociedade, afinal, não só perceber e conhecer a explicam, mas também o fazer, o agir, portanto a vontade de atuar, a força motriz do agir em sociedade. Assim como sentimento e ideia, vontade também é indissociável da pessoa humana, do indivíduo socializado.

A essa altura já podemos registrar que os autores não são inocentes nem ignoram a violência social, apenas não concebem o conflito como explicação da vida em sociedade. Chama nossa atenção que os autores não partem de um modelo social, de um conceito de civilidade normativo que deve nortear as análises sociológicas. Cláudio e Solange apostam no processo de aprendizagem dos papéis sociais, na imitação como meio que viabiliza "controle social como equilíbrio da organização social" (SOUTO; SOUTO, 2003, p. 32). Assim diferentes sociedades desenvolvem diferentes instrumentos de socialização.

Nascemos associais. O fator tempo, agregado ao espaço, à intensidade, à frequência norteiam expectativas de comportamento, viabilizam a construção de uma "linguagem comum que leva o grupo social a agir dentro de padrões" (SOUTO; SOUTO, 2003, p. 34), que promovem a interiorização de normas, padrões, portanto a percepção, concepção e motivação ao agir em conformidade com os elementos culturais, e evitar o conflito. A conformidade, fique claro, não se confunde com submissão, com uma adaptação por hostilidade. Há processos sociais de acomodação, assimilação, acordo, fusão, tolerância, mas também conflito, violência, oposição. Justamente pautados pelo interSIV é que este ou aquele processo social tem mais lugar num dado momento e espaço social. O SIV de justiça nutre estímulos, servem de guia e controlam movimentos sociais. Assim é que o conhecer, o sentir e o atual pautam o sentimento-ideia de justiça movendo o social humano pela concepção de aprovação e reprovação. Ocorre que essa concepção não se reduz ao uso ou ameaça da força, de sanções negativas. Os autores lembram que há sanção 


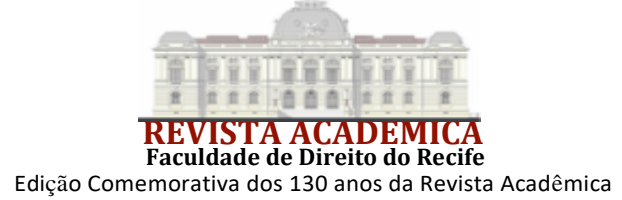

positiva. Neste ponto, a teoria se equaciona por uma visão de sociedade como guiada pelo justo, porém há uma mobilidade do SIV de justiça, mobilidade esta que norteia a visão de legitimidade, a qual "não é o que é conforme a lei, mas o que é fundado sobre o direito" (SOUTO; SOUTO, 2003, p. 37). Sendo assim, os autores afirmam que
se quisermos chamar de direito social, direito vivo, ou simplesmente direito a associação do sentimento do que deve ser (justiça) com uma ideia de acordo com o conhecimento científico (a ideia mais segura correta relativa a esse dever ser), o direito assim entendido é, decerto, um controlo social de maior importância, mesmo quando não instrumentalizado de força física (SOUTO, 2003, p. 200-201).

A eficácia do direito não resulta necessariamente do uso da força, nem da coercibilidade, a ameaça do uso da força. Força não compõe elemento essencial ao fenômeno social jurídico, ela não necessariamente atua sobre a expectativa normativa porque se assim for, a sociologia do direito não teria como explicar as mudanças sociais. A hipótese da sanção como reprovação justa. Para os autores, a violência física, a selvageria, a violência psicológica não guardam qualquer relação com o direito porque eliminam, não só o sentimento de agradabilidade, o sentimento de justiça, mas também a ideia de justiça, o que invalida o elemento conhecimento científico como norteador do direito (SOUTO; SOUTO, 2003, p. 229). Não se trata, portanto, de qualquer saber, de qualquer capacidade ou força persuasiva, ou de mecanismos de conversão de pessoas a um sentimento e ideia de justiça, afinal, há o elemento vontade e, essa vontade, não poder ser obtida a força, pelo medo, ameaça, mas pela compreensão, pela racionalidade.

Assim é que, os autores não acatam concepções e explicações do direito procedimentalistas, como predomina na filosofia, nas teorias da justiça e mesmo na sociologia atual. A teoria é substancialista porque defende que o interSIV equaciona um conteúdo de dever ser, um conteúdo do que é justo. Assim, o direito estatal é uma forma de expressão do fenômeno social jurídico e jamais todo o direito, inclusive porque há lei emanada do poder estatal que não é direito mesmo tendo obedecido ao devido processo legal. Do mesmo modo que há decisão judiciária que não é direito mesmo decorrente do devido processo legal. Assim é porque uma definição do direito não é condizente mesmo que sociológico, como é o caso de direito é um fenômeno social, pois é uma definição tão ampla que pode alcançar qualquer conteúdo normativo, o que promoveria insegurança na prática jurídica, bem como no cotidiano social. Com isso, Cláudio e Solange definem direito como a

regra de direito aquela em consonância com o sentimento humano de justiça e com dados de conhecimento científico-empírico; e seria conduta humana jurídica aquela em consonância com a norma do direito (SOUTO; SOUTO, 2003, 221).

Observem que nessa proposta o "medo de ser excluído de uma organização, os castigos e recompensas em outro mundo, podem ser mais efetivos do que um aparelho político cujo funcionamento coercitivo não é sempre predizível com certeza” (SOUTO; SOUTO, 2003, p. 207). Assim é que a força não é um elemento que integra a definição de direito dos autores.

Por fim, concluímos estas reflexões com a passagem dos autores:

Cláudio Souto e Solange Souto chamam aquilo a que os juristas se referem com a expressão "direito positivo", simplesmente de formas coercíveis (lei, costume, decisão judicial etc.) - sendo "coercível", simplesmente "o que pode ser coagido" -, pois o conteúdo desse "direito positivo", ou dessas formas de coercibilidade, nem sempre é justo e científico, podendo antes consagrar o torto. De outra parte, a regra em consonância com o sentimento humano de justiça e com dados de ciência pode manifestar-se socialmente sem ser sob qualquer forma de coercibilidade estatal e apenas sob a forma da simples palavra, escrita ou oral (SOUTO; SOUTO, 2003, 221).

\section{CONCLUSÃO}

Como constante no título dessas reflexões, apresentamos a SAGA, A 


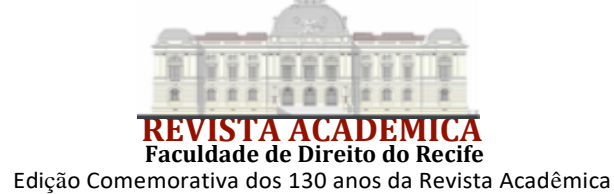

SUBSTANCIALIDADE e O INTERSIV de Cláudio Souto e Solange Souto, com o que demonstramos a importância dos autores na criação, desenvolvimento e continuidade do pensar sociologicamente o direito no Brasil; que a perspectiva substancialista tem seu lugar na explicação sociológica; que o direito não se reduz ao formalismo jurídico porque o social não se reduz a imposições, antes, o social é união e fatores agressivos afastam as pessoas e, ao se distanciarem deixam de formar o direito, o siv de dever justo.

Claro muito mais elementos e questões merecem ser trabalhadas e exploradas nas obras de Cláudio e Solange. Os ensinamentos e exemplos de vida profissional dedicada à pesquisa jurídica estimula e motiva que outros trilhem a via profissional de pesquisadores.

Assim, concluímos nossas reflexões agradecendo Cláudio Souto e Solange Souto pelo legado, pelo exemplo e por tudo que representam para a pesquisa jurídica nacional e internacional.

\section{REFERÊNCIAS}

ADEODATO, João Maurício. O positivismo culturalista da Escola do Recife. Novos Estudos Jurídicos, v. 8, n. 2, p. 303-326, maio/ago. 2003.

APOSTOLOVA, Bistra Stefanova. O debate sobre a fundação dos cursos jurídicos no Brasil (1823-1827). Uma reavaliação. Varia Historia, Belo Horizonte, v. 33, n. 62, p. 419-458, mai/ago 2017. DOI: http://dx.doi.org/10.1590/0104-87752017000200007.

BRASIL. Imperador Constitucional e Defensor Perpetuo do Brazil. Lei de 11 de agosto de 1827. Crêa dous Cursos de sciencias Juridicas e Sociaes, um na cidade de S. Paulo e outro na de Olinda. Disponível em: http://www.planalto.gov.br/ccivil_03/leis/lim/LIM.-11-08-1827.htm. Acesso em: 03 jun. 2021.

CARNEIRO FILHO, Humberto João; PEREIRA, Ingrid Rique da Escóssia; FARIAS, Diogo Stanley Vasconcelos de; CALLADO FILHO, Inácio José Buonafina. Acesso à cultura e preservação de lugares de memória na Faculdade de Direito do Recife. Revista Expressa Extensão, v.24, n. 1, p. 06-24, jan./abr. 2019.

IANNI, Octavio. O pensamento social brasileiro. Bauru-SP: EdUSC/ANPOCS, 2004.

JUNQUEIRA, Eliane Botelho. Entrevista com Cláudio Souto e Solange Souto. RBSD - Revista Brasileira de Sociologia do Direito, v. 8, n. 3, p. 305-339, set./dez. 2021.

PESSOA, Ariel Engel. A Faculdade de Direito do Recife no Império Brasileiro (1827-1889): lista de diretores e lentes catedráticos. Revista Acadêmica da Faculdade de Direito do Recife, v. 92, n. 2, p. 209-231, dez. 2020. Disponível em:

https://periodicos.ufpe.br/revistas/ACADEMICA/article/view/248871. Acesso em: 03 jun. 2021.

SOUTO, Cláudio. Crise social e direito do trabalho. In: I SEMANA DE ESTUDOS JURÍDICOS DO RECIFE. Recife, 1952. p. 5-24.

SOUTO, Cláudio. O direito contra a realidade social. In: III SEMANA BRASILEIRA DE ESTUDOS JURÍDICOS, Salvador, Bahia, 1953. p. 13-29.

SOUTO, Cláudio; SOUTO, Solange. Mudança social e direito. Comunicações, PIMES, UFPE, Recife, 1974. p. 1-65. 
SOUTO, Cláudio; SOUTO, Solange. Social interaction: an approach from the normative. ARSP: Archiv für Rechts-und Sozialphilosophie/Archives for Philosophy of Law and Social Philosophy, 1975. p. 181-199. n. 1.

SOUTO, Cláudio. Teoria sociológica do direito e prática forense. Porto Alegre: SAFE, 1977.

SOUTO, Cláudio. Por uma ciência social rigurosa del derecho. Sociología y Psicología Jurídicas, Barcelona, 1983. p. 7-20.

SOUTO, Cláudio; SOUTO, Solange. A explicação sociológica: uma introdução à Sociologia. São Paulo: Pedagógica e Universitária, 1985.

SOUTO, Cláudio. Interdisciplinariedade: o caso das ciências jurídicas básicas. Ciência \& Trópicos, Recife, v. 14, n. 1, p. 61-69, jan./jun. 1986.

SOUTO, Cláudio. Educação jurídica e conservadorismo acadêmico. In: LYRA, Doreodó Araújo. Desordem e progresso: estudos em homenagem a Roberto Lyra Filho. Porto Alegre: SAFE, 1987a. p. 197-213.

SOUTO, Cláudio. O que é pensar sociologicamente. São Paulo: E.P.U., 1987b.

SOUTO, Cláudio; SOUTO, Solange; HARTEL, Dietlinde. Mudança social e mentalidade jurídica: uma pesquisa empírica. Recife: CNPq-Editora Massangana, 1988.

SOUTO, Cláudio. Magistratura brasileira e ideologia formalista. Seqüência: Estudos Jurídicos e Políticos, v. 10, n. 19, p. 9-36, 1989.

SOUTO, Cláudio; SOUTO, Solange. Formalidade e informalidade no controle social pelo direito. Revista da ESMAPE (Escola Superior da Magistratura de Pernambuco), v. 2, n. 4, p. 435-448, abr./jun.1997.

SOUTO, Cláudio; SOUTO, Solange. Sociologia do direito. Uma visão substantiva. Porto Alegre: SAFE, 2003.

SOUTO, Cláudio. Sobre a pesquisa científica em direito. Revista Brasileira de Sociologia do Direito (RBSD-ABraSD), v. 1, n. 1, p. 38-49, jan./jul. 2014.

SOUTO, Cláudio. Breve histórico da sociologia jurídica na Faculdade de Direito do Recife.

Revista Acadêmica - Faculdade de Direito do Recife, v. 88, n. 1, p. 22-38, jan./jun. 2016.

SOUTO, Cláudio. For a general theoretical unified axiomatic reduction of the natural spaces. RBSD - Revista Brasileira de Sociologia do Direito, v. 6, n. 2, p. 2-12, maio/ago. 2019.

SOUTO, Solange. Sociedade e controle social. Recife: Unicap, 1971.

SOUTO, Solange. A perspectiva formal e a perspectiva científico-social do direito. Vox Legis, v. 145, p. 29-37, jan. 1981. 
Letras, 2019.

STAMFORD DA SILVA, Artur. E por falar em teoria jurídica, onde anda a cientificidade do direito? Revista da Faculdade de Direito de Caruaru, ASCES, ano 33, v. 24, n. 1, p. 63-78, 2002.

STAMFORD DA SILVA, Artur. Tecnicismo experiencial forense, o saber acadêmico e o saber científico no Direito. A pesquisa como habilidade profissional. Anuário do Programa de Pósgraduação em Direito da UFPE, Recife, EdUFPE, v. 15, p. 27-54, 2005.

VENÂNCIO FILHO, Alberto. Das arcadas ao bacharelismo. São Paulo: Perspectiva, 2011.

WARAT, Alberto. O senso comum teórico dos juristas. Sequência, Florianópolis, v. 03, n. 05, 1982. 